\title{
Article
}

\section{Sharing the pi: are incentives an effective method of attracting a more diverse science festival audience?}

\author{
Canovan, Cherry
}

Available at http://clok.uclan.ac.uk/32877/

Canovan, Cherry ORCID: 0000-0002-9751-5646 (2020) Sharing the pi: are incentives an effective method of attracting a more diverse science festival audience? International Journal of Science Education, Part B: Communication and Public Engagement, 10 (3). pp. 217-231. ISSN 2154-8455

It is advisable to refer to the publisher's version if you intend to cite from the work. http://dx.doi.org/10.1080/21548455.2020.1753126

For more information about UCLan's research in this area go to http://www.uclan.ac.uk/researchgroups/ and search for <name of research Group>.

For information about Research generally at UCLan please go to http://www.uclan.ac.uk/research/

All outputs in CLoK are protected by Intellectual Property Rights law, including Copyright law. Copyright, IPR and Moral Rights for the works on this site are retained by the individual authors and/or other copyright owners. Terms and conditions for use of this material are defined in the policies page.

\section{CLoK}

Central Lancashire online Knowledge www.clok.uclan.ac.uk

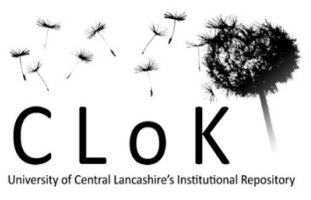




\title{
Sharing the pi: are incentives an effective method of attracting a more diverse science festival audience?
}

\author{
Cherry Canovan ${ }^{\mathrm{a} *}$
}

${ }^{a}$ Communications and Engagement, University of Central Lancashire, Preston, UK

CB106 Chandler Building, University of Central Lancashire, Preston PR1 2HE, ccanovan@uclan.ac.uk

Twitter: @DrCherryCanovan

ORCiD: 0000-0002-9751-5646

*corresponding author

Cherry Canovan is a research associate at the University of Central Lancashire. She obtained her PhD in Mathematical Physics from Lancaster University and previously worked as an education journalist. Her research interests include the impacts of science festivals, as well as widening participation in STEM and higher education more generally.

Word count: c.7,650 


\title{
Sharing the pi: are incentives an effective method of attracting a more diverse science festival audience?
}

\author{
Science festivals are seen as a success story for public engagement with science, \\ with numbers rapidly growing. However research has shown that attendees at \\ such events tend to be more affluent, better-educated and more interested in \\ science than populations at large. This has led to calls for research into how \\ festivals can widen participation beyond the already engaged. This paper details \\ the efforts of one festival to attract a more diverse audience through the use of a \\ targeted 'Community Pass', offering attendees a free lunch, as well as by \\ undertaking analysis of the characteristics that made individuals more likely to \\ attend. The research shows that such a scheme has the capacity to attract a very \\ different audience to visit, albeit on a small scale due to cost implications. \\ Working with existing community groups was shown to be the most effective \\ method of distributing the passes, with recipients valuing a personal interaction \\ with the distributor. There is also some suggestion that the incentive might \\ nudge audiences who had a 'fragile' intention to attend the festival into actually \\ visiting, by making it financially easier for them to do so. However more \\ research is needed into whether larger-scale measures, such as employing \\ community outreach officers, could have a more significant effect on overall \\ attendance profiles.
}

Keywords: science festivals; science capital; widening participation; public engagement with science

\section{Introduction}

Science festivals are an increasingly prominent phenomenon, held in countries across the world and attracting millions of visitors annually. They are diverse in nature but most share the aims of enthusing and inspiring members of the public about science, and informing the wider population about current scientific research. However the nature of the 'public' which is addressed by the science festival sector has recently been questioned by studies finding that most visitors to such events are already scientifically engaged. Furthermore, festival attendees tend to be relatively affluent and more highly 
educated than the general populace.

These findings have led to calls for science festivals to focus on widening their audience base, and for research to be done into the best ways of achieving this goal. This paper looks at the efforts of once such festival, the Lancashire Science Festival, to attract visitors from low-participation groups. It studies the methods used in the context of the existing literature on the related area of widening access to museums, analyses the successes and shortcomings of the approach taken, and makes suggestions for ways in which the process can be applied and potentially improved by the science festival sector more widely.

\section{Science festival audiences}

Science festivals have, in many ways, been a success story of an increasing commitment to public engagement with science, particularly in Europe and North America. Numbers of events have increased dramatically over the last two decades and host millions of visitors every year (Bultitude, 2014; Science Festival Alliance, 2017; UK Science Festivals Network, 2018).

However in recent years the sector has come under increasing criticism for failing to reach out to an audience beyond the already-engaged. In their paper "Preaching to the scientifically converted: evaluating inclusivity in science festival audiences," Kennedy, Jensen and Verbeke (Kennedy, Jensen, \& Verbeke, 2017) analysed data from three UK science festivals, looking at factors such as demographics, cultural engagement, science attitudes and education. The authors found that:

\footnotetext{
"Not only were visitors already highly engaged in cultural and scientific events prior to their science festival attendance, but they also displayed high pre-visit levels of interest in science... science festival audience members were already convinced of the value of science prior to attending. In addition, we found that
} 
adult attendees were more highly educated and economically advantaged than the UK population."

In the three festivals studied by Kennedy et al, between $71-80 \%$ of attendees held an undergraduate degree, with more than $80 \%$ indicating that they were interested in science before attending.

In North America, Rose et al performed a similar analysis at the Wisconsin Science Festival (Rose, Korzekwa, Brossard, Scheufele, \& Heisler, 2017) by comparing attendees with the Wisconsin population as a whole. The study found that festival attendees were much more likely to hold college degrees than the population as a whole (91\% compared to $40 \%)$. They were also more liberal, deferent to scientific authority and more trusting of university scientists.

Most recently, Nielsen, Gathings and Peterman (Nielsen, Gathings, \& Peterman, 2019) examined data from around 10,000 attendees from 24 US festivals as part of the EvalFest project. They found that typical festival attendees were middle class and highly educated, stating that although festivals were reaching new audiences, with a majority of each year's visitors not having visited before,

"...attendees are lacking in diversity and might be categorized as the "usual suspects' for public science events".

Both Nielsen et al and Kennedy et al issued calls to action in their conclusions. Nielsen et al urge the festival sector to ask:

\footnotetext{
"Are we satisfied with new audiences at our events even if they lack diversity, and why or why not? Should we consider adding audience diversity to our mission statements, and if so, what are effective strategies for starting to achieve diversityrelated goals?"
}

Meanwhile Kennedy et al state: 
"Scientists, funding agencies, and public science communication organizations need to acknowledge these problems, re-focusing their efforts on the types of people they reach and with what effects... Moreover, effective social inclusion efforts should be viewed as a key mark of event quality."

And they call for further research into how the challenge of social inclusion at festivals can be addressed:

"It would also be helpful to document promising practices for inclusion from events around the globe, and to share these practices as a way of encouraging further evolution in the events."

This paper is a response to this call, detailing the methods and effectiveness of one festival's attempts to improve access for low-participation audiences.

\section{Science capital and socio-economic status}

When considering the demographics of science festival audiences, it is helpful to enlist the prism of 'science capital' developed by Archer at al (Archer et al., 2012; Archer, Dawson, DeWitt, Seakins, \& Wong, 2015; DeWitt, Archer, \& Mau, 2016). Archer et al characterise science capital as a measure that

“...goes beyond science-related cultural capital and knowledge, and beyond attitudes to science, to also encompass science-related social capital and behaviors and practices." (Archer et al., 2015.)

The authors construct an index of science capital containing measures of science-related cultural capital (eg scientific literacy, knowledge about transferability of science qualifications), science-related behaviours (consumption of science media, participation in out-of-school learning) and science-related social capital (knowing someone who works in a science job, talking to others about science). 
When the index was tested on secondary school pupils, the authors found that only $5 \%$ of the sample had 'high' science capital, with $68 \%$ having a medium score and the remaining $27 \%$ low science capital. The high science capital group were significantly more likely to say that they would like to study science at university and that they were interested in working in science-related jobs in the future.

The index is somewhat related to socio-economic status, in that pupils with high science capital tend to come from homes with very high levels of cultural capital, while those with low science capital are disproportionately from socially less advantaged backgrounds. However those with medium levels of science capital are largely representative of wider society in terms of SES, demonstrating that relative affluence is not a sufficient condition for high science capital.

The finding that pupils with high science capital were more likely to be considering choices that might lead to a science career is indicative of the problems facing those who would broaden access to such careers beyond a small cohort. It is easy to see how a multitude of factors combine to support this group into science careers while incrementally discouraging others.

By aiming to raise levels of interest in science and expose members of the public to scientists, science festivals could be one avenue through which these disparities in science capital are addressed. There is some evidence supporting this effect; in a previous study, (Canovan, 2019) we found that attending a family science festival led to parents reporting improved attitudes to science and increased knowledge of the breadth of science careers. The paper notes that

\footnotetext{
“...attendance at such an event can have a significant effect on parental views of science, with $70 \%$ of parents reporting a positive impact on their perception. This effect was particularly marked among parents from more deprived areas; those of lower SES were significantly more likely to report an improved perception of
} 
science. This is important because low SES is a proxy for low science capital, and young people from these groups are more strongly influenced by their parents' attitudes when choosing whether to participate in post-compulsory science.”

Science festivals will, however, only be a useful tool for increasing science capital in low-participation groups if they can attract those groups to attend in the first place. The methods by which this can be achieved, therefore, merits our attention.

\section{The Lancashire Science Festival}

The Lancashire Science Festival (LSF) is a medium-sized festival held every summer at the University of Central Lancashire's Preston, UK campus. Running since 2012, it is held over three days, two of which are dedicated to school parties with the third open to all. The event is aimed at primary-age children and their families and typically attracts around 5-6,000 pupils on the school days, and 7-8,000 members of the public on the final family day.

Since 2017, the event has been recording several pieces of information about every family that attends, including postcode, whether or not the person doing the booking has a degree, and that person's level of self-reported information about science. This information is used to investigate the profile of attendees at the festival, with postcode information used to assess each attending family's socio-economic status (SES) via use of the UK government's Index of Multiple Deprivation (IMD).

The percentage of attendees with a degree was remarkably stable across the three years of this study at $64 \%$ in 2017,2018 and 2019. This compares with census data showing that $27 \%$ of adults across England and Wales hold a degree, and $25 \%$ across 
Lancashire $^{1}$. Additionally, the percentage saying they were fairly well informed or very well informed about science was $72 \%$ in $2017,71 \%$ in 2018 and $68 \%$ in 2019 . Visitors felt themselves to be better informed about science than Britons as a whole; a similar question asked in the government's 2014 Public Attitudes to Science Survey ${ }^{2}$ gave the corresponding national figure as $45 \%$, and $50 \%$ for the North West. The LSF, therefore, attracted visitors with much higher levels of education and scientific literacy than the populace as a whole.

In terms of measures of deprivation, families from postcodes of with the lowest levels of deprivation were more strongly represented among attendees. In 2017, 25\% of families attending were from IMD d1-3 (high deprivation) areas, while 41\% were from IMD d8-10 (low deprivation) postcodes. The corresponding figures for 2018 were $29 \%$ and $38 \%$, and for $201925 \%$ and $41 \%$. As just under half (43\%) of attending families come from central Preston (PR1 and PR2) postcodes, and given the demographics of the local area of Preston, where $64 \%$ of households are in wards $^{3}$ with IMD d1-3, this is likely to be an even greater underrepresentation than it appears.

Analysis by researchers after the 2017 event found that in the immediate surrounds of the festival site, ie the city of Preston, there was a noticeable difference in levels of attendance between more and less affluent areas. Figure 1 is a map of central Preston. The light grey shaded areas on the left-hand side of the map are the postcode sectors where more than $1 \%$ of families attended LSF in 2017. The darker grey areas are the Preston wards which are in the lowest decile (d1) of IMD by ward nationally. As can be seen, the two areas tessellate remarkably well, showing the extent to which festival attendance in the local area is correlated with relative affluence.

\footnotetext{
${ }^{1}$ https://www.ons.gov.uk/census/2011census

${ }^{2}$ https://www.gov.uk/government/publications/public-attitudes-to-science-2014

${ }^{3}$ Although IMD at ward level and individual postcode level are not directly comparable, we can use the ward-level data as a useful indication of the demographics of the local area.
} 


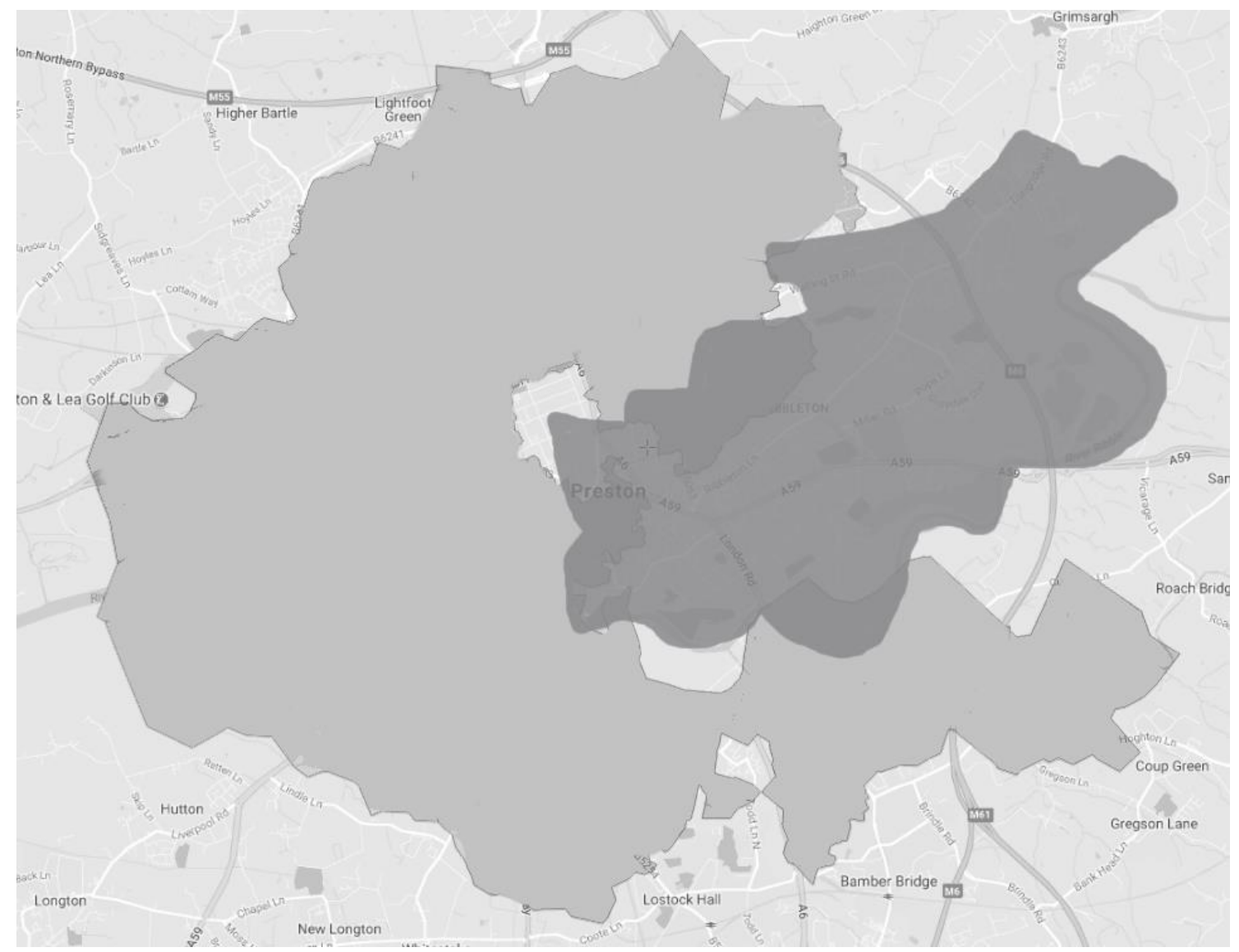

Figure 1: Areas of Preston with higher rates of LSF attendance. Light grey areas are those where more than $1 \%$ of families attended LSF in 2017. Darker grey areas are local wards which are in IMD d1 nationally.

Given this, and the demographic attendance data detailed above, organisers determined to initiate a project to attract families from lower-SES areas of the festival's immediate environment to attend in greater numbers. The project ran during the 2018 iteration of the festival and, with some amendments, on through the 2019 edition.

As can be seen from the 2018 and 2019 demographic data given in this section, the aim of the project was not to effect a wholesale change in the visitor profile to the LSF. Instead, it was to test the effectiveness of a set of measures in attracting visitors from underrepresented communities to attend. 


\section{Equity of access and economic cost}

As this pilot is predicated on the fact that there is, as yet, little research into the best methods to widen attendance from low-participation groups at science festivals (Kennedy et al., 2017), we must look elsewhere in the literature for grounding as to possible methods, and a related place to start is with efforts to broaden attendance at museums and science centres.

In a study of how museums and science centres in the US aimed to attract a more diverse audience, Feinstein and Meshoulam (Feinstein \& Meshoulam, 2014) found that the institutions pursued a number of avenues such as aiming to employ staff from a variety of backgrounds, making exhibits more engaging to target communities, and taking exhibits and activities out of the museum and into communities. However two main strategies for directly attracting a diversity of attendees were employed; financial help in the form of free passes or other price reductions, and staffing, for example employing community liaison officers. These, then, seemed obvious possible places for the LSF to start when trying to boost participation from low-attendance communities.

Due to limitation of resources and the logistical implications, the organisation was unable either to employ more staff to act as community liaison representatives or to redeploy existing members of staff in this way. It was decided, therefore, to try to provide financial help to target groups. As the festival is already a free event, LSF organisers decided to attempt to lower the overall costs of attending for these groups by subsidising the day out via the medium of a lunch voucher.

Although providing financial help can provide a relatively cheap and easy way to attempt to widen participation, the evidence on how effective it is is variable. Feinstein and Meshoulam themselves note that

"Despite the considerable energy that went into addressing logistical and financial barriers, participants from most organizations... felt that culture was the greatest 
barrier to museum attendance. In this context, "culture" referred not to a specific cultural group, but to a pervasive discomfort or lack of familiarity with $\mathrm{ISE}^{4}$ organizations - the perception that "people like me don't go to science museums and science centers."

Despite this, one might maintain that financial barriers are worth addressing if they form a barrier, even if not the greatest one. However there has been some pushback against the idea that lowering prices improves the diversity of a museum's audience. An example of this is given by the UK's national museums, for which the government scrapped all entrance charges in 2001. A report by market research company MORI in 2002 (Martin, 2002) found that there had, in fact, "been a rise in museum visiting among those in the $\mathrm{DE}^{5}$ social classes (those where the head of household is an unskilled manual worker) from $20 \%$ in 2001 to $25 \%$ in 2002 ". However, there was a concomitant increase among other groups, leading to MORI to conclude that

"...while the number of people coming through the door might have dramatically increased, the profile of a typical 'population' of museum or gallery visitors has remained relatively stable, and firmly biased in favour of the 'traditional' visitor groups."

MORI also asked those who were not attending why this was the case; very few respondents (8\%) cited costs such as travel and food and drink, with the most popular response (43\%) being a lack of time. However, although MORI do not disaggregate these responses by income group, the report states that "Transport and money issues do still prevent some people from visiting (predominantly DEs, those without formal

\footnotetext{
${ }^{4}$ Informal science education

${ }^{5}$ The NRS (National Readership Survey) Social Grade measures demographics in classes A, B, C1, C2, D and E - see http://www.nrs.co.uk/nrs-print/lifestyle-and-classificationdata/social-grade/
} 
qualifications, and people living in the north of England)," indicating that our target group may, in fact, be affected by such concerns.

A 2016 report by the Association of Independent Museums (AIM) on the impact of charging for museum admission (Association of Independent Museums, 2016), found that "there is very little difference between the proportions of different social grades of visitors to free admission sites and to paid admission sites". However the report's analysis also found that museums were concerned that charging had a negative impact on visits from local people, stating that:

"The concern about the impact of charging on local people is supported by AIM Visitor Verdict data which shows local visitors (i.e. visitors from same county as the museum) accounting for a higher proportion of visitors to free admission sites ( $44 \%$ of visitors are from the same county), than paid admission (26\% of visitors are from the same county)."

In terms of widening participation, this factor may be of significant concern to museums, and by extension other cultural institutions, that are located in areas of higher deprivation. As one of our aims in this study was to see if more families from the local area could be attracted to the LSF, this may be a significant point.

Mixed evidence is also found in the work of Kirchberg (Kirchberg, 1998) who analysed the results of a survey among German respondents on what they perceived to be the main barriers to visiting a museum. The author found that " "...people in the lowest income bracket regard museum entrance fees as a very important barrier almost five times as much as people in the highest income bracket". Additional analysis of other variables led to the conclusion that:

"This study clearly demonstrates that the variables income, education and occupational status do have a combined impact on the assessment of price as a barrier to museum attendance." 
Kirchberg then, however, went on to note that as most German museums at the time charged low or no entrance fees:

“...the number of museum visits cannot be objectively related to household lack of funds as these museums do not have a higher attendance rate. Subjectively, however, this analysis demonstrates a link as the number of visits to a museum correlates with the "imagined" price".

The author then references Bourdeusian analysis to suggest "that income is not the affecting factor for barrier assessment but rather that different life style preferences may be affected by different educational and occupational influence". This has led to this paper being used as evidence that pricing is not an issue when it comes to attracting underrepresented groups (eg Dilenschneider, 2015). However, while we do not doubt that family habitus among such groups is an important factor in the decision as to whether to attend a museum or related cultural experience, we also feel impelled to point out that in fact the cost of visiting a free museum is rarely nil, particularly for a family with children, for whom transport expenses and refreshments may add up to a considerable amount.

To summarise the above: MORI found that making museums free did not have much impact on the socioeconomic (SE) profile of visitors, but that "money issues" prevented some people, including WP target groups, from visiting. AIM found that charging and non-charging museums had similar socio-economic visitor profiles, but that charging was offputting to visitors who were local to the museum. Kirchberg found that those of low SES saw cost as a barrier to museum visitation; however because free museums did not display a greater rate of visits by these groups, he concluded that income was not the deciding factor. However we argue that for families, museum visits are rarely truly free due to the additional costs associated with trips out. 
Overall, then, we find that the evidence of the literature as regards the financial aspects of museum visitation is mixed; we therefore feel that the effects of a financial intervention to try to improve science festival audience diversity are worth investigating. In addition, we felt that the question of what factors affected families' attendance at the LSF was worthy of further study.

\section{Methods}

In an effort to widen participation to harder-to-reach groups, festival organisers decided to introduce a 'Community Pass', which would incentivise recipients to attend the festival. They also embarked on further research into the factors that made families more or less likely to attend the event.

\section{Audience analysis}

One aim of the project was to analyse how strongly an intention to attend the festival translated into actually attending. This study was made possible by the organisational structures of the Lancashire Science Festival, which asks visitors to pre-register to attend the event. Whether registrants actually attend on the day is recorded at check-in desks, thus allowing a comparison between two groups - those who register and do attend, and those who register and do not ${ }^{6}$. Researchers studied these groups over two iterations of the festival, in 2017 and 2018, looking at factors including level of education, scientific confidence, measures of deprivation, and previous festival attendance. They then took these findings and attempted to address issues arising using extra email communications in 2019.

\footnotetext{
${ }^{6}$ It was also possible to turn up on the day without pre-registering; however these families were excluded from this part of the analysis.
} 


\section{Community Pass 2018}

The first iteration of this scheme was introduced at the 2018 LSF. Community Passes were printed giving recipients a $£ 10$ meal voucher, intended to make the day out cheaper for lower-income families. They also entitled the holder to a pack of science activities to be done at home.

Because of the costs associated with the scheme, and uncertainty as to what take-up would be, only 1,500 passes were printed. These were distributed through schools in target areas, by community groups, and via a letterbox drop.

The Community Pass 2018 was designed as in Figure 2. As can be seen, the reference to it entitling the holder to a lunch voucher and science pack was not very prominent. Each pass was individually numbered, allowing researchers to track which method of distributing the passes resulted in the greatest proportion being used.

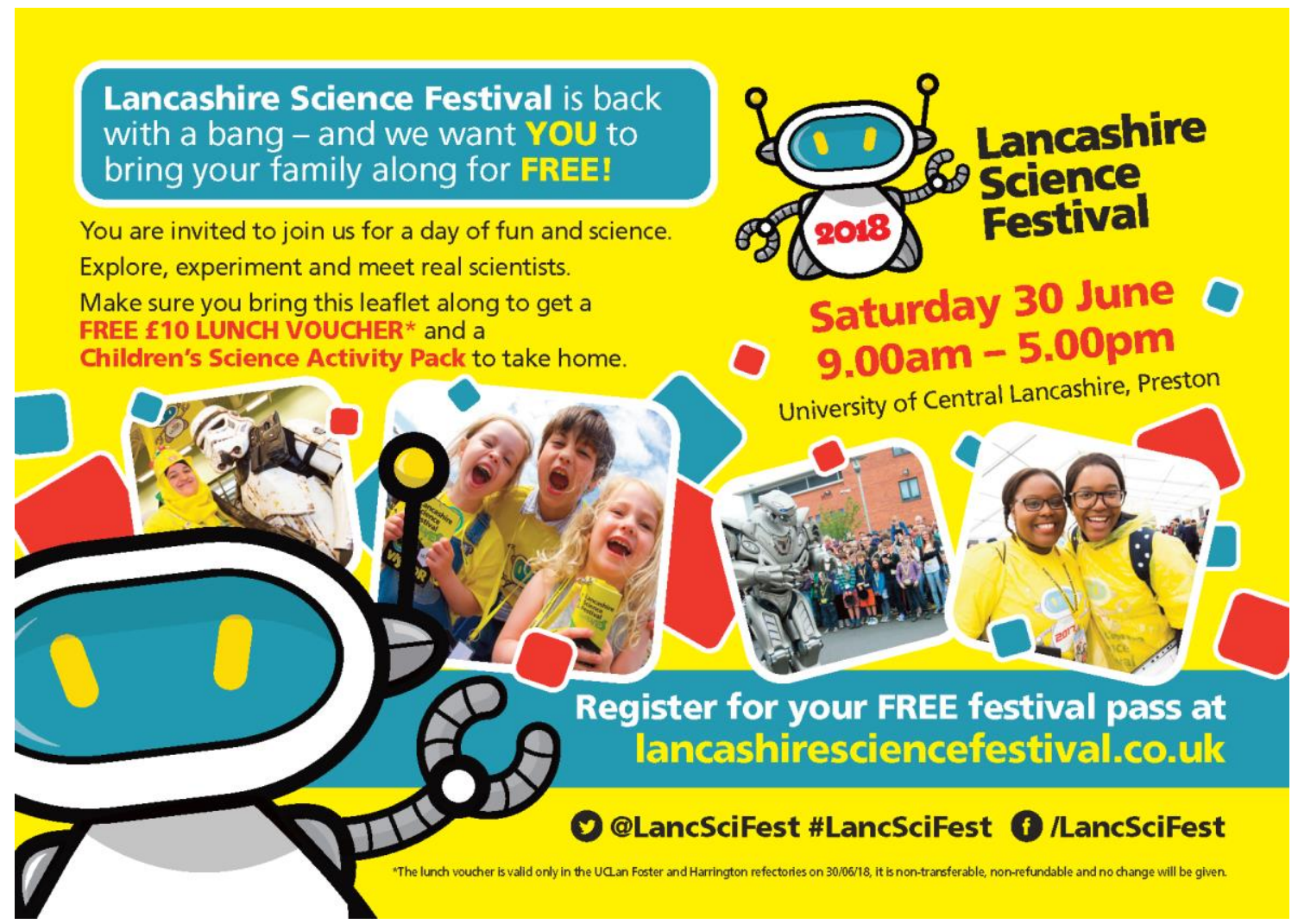

Figure 2: Community Pass 2018 
Three routes were chosen for distribution of passes. The majority (993) were given out via schools in target areas of south-east Preston which had high levels of Pupil Premium, the extra funding given by the UK government to support the most disadvantaged children. Passes were put in the book bags of Key Stage 2 (7-11) children who were not already visiting the festival on a school trip. This option was chosen as a relatively straightforward way of distributing large numbers of passes, particularly as the organisers had pre-existing relationships with several schools in the local area.

A further 375 passes were distributed via community organisations, including youth groups, children's centres, housing associations, event organisers and foster families. These organisations were more time-consuming to identify and most were only able to distribute a small number of passes.

The remaining 132 passes were distributed via a letterbox drop in a low HEparticipation area of Preston within walking distance of the festival site.

On the day of the festival, Community Pass holders signed in with the main group of visitors and were directed to a separate desk where their pass was stamped, allowing them to use it as a voucher. Their pass number was recorded, a few details were taken about recipients, and families were given a voucher to collect a science pack. After the event, pass holders were sent a link to an online survey containing further questions about their experience.

\section{Community Pass 2019}

The Community Pass scheme was revised for 2019 in an attempt to improve takeup. The design was altered to make the offer of a $£ 10$ lunch voucher more obvious, and more passes $(2,500)$ were printed. For logistical reasons, it was decided not to make the science pack part of the offer in 2019. 
Figure 3 shows the design for the Community Pass 2019, with a more prominent position for the lunch voucher offer. Passes were again individually numbered.

You are invited to join us for a day of fun and science. Explore, experiment and meet real scientists. Make sure you bring this leaflet along to claim your

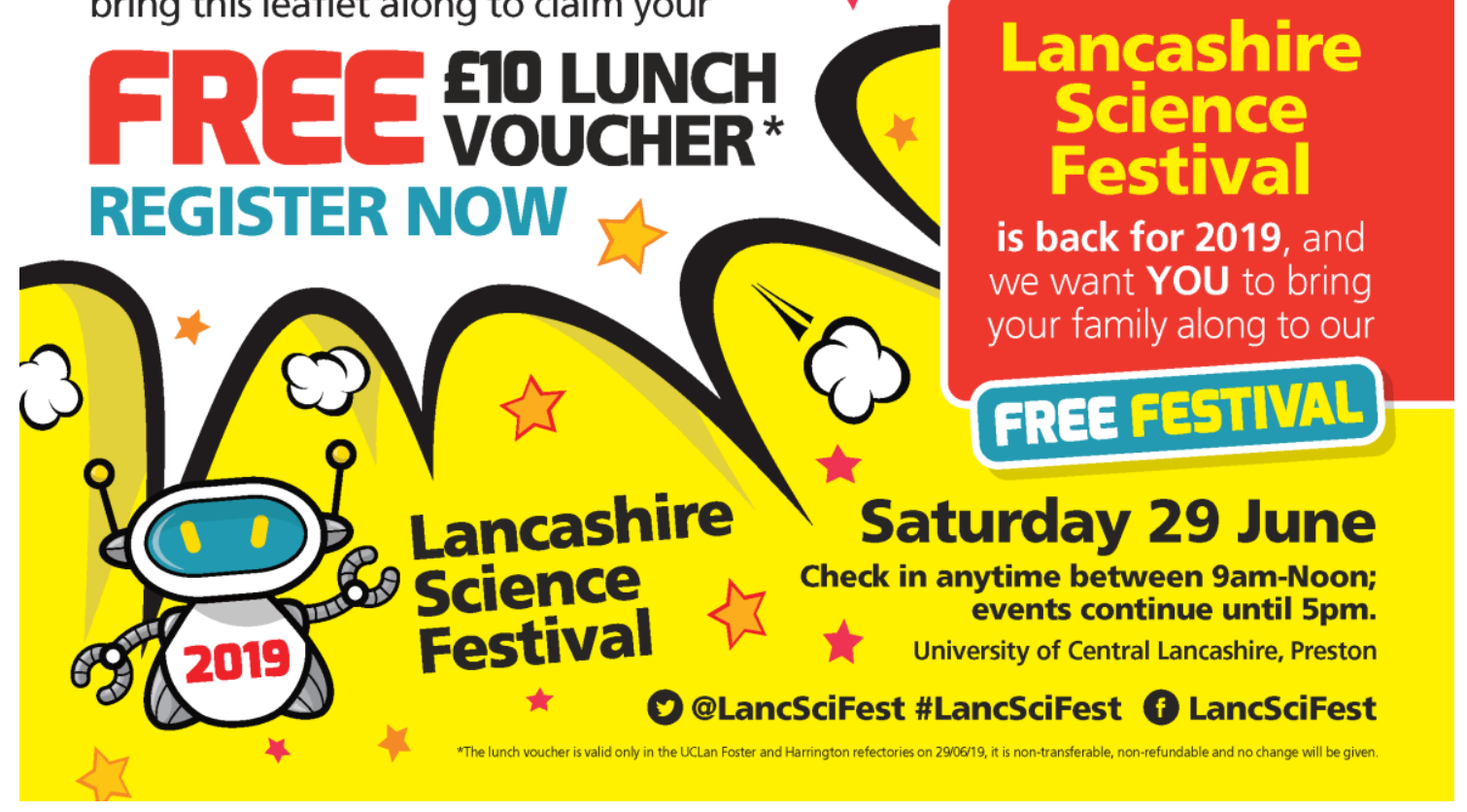

Figure 3: Community Pass 2019

Routes for distribution differed from the previous year with 1,000 being distributed via a local children's charity, Cash for Kids, with contacts in a network of community organisations. As well as community groups, the charity worked with schools to distribute the passes to children attracting the Pupil Premium. The remaining 1,500 were sent out via a targeted mailing. Arrangements on the day of the festival and afterwards were similar to those for 2018. 


\section{Results}

\section{'Fragile' intentions to attend}

An analysis of pre-festival registrants for 2017 and 2018 showed that in both years, a large proportion did not go on to attend - 44\% in 2017 and 55\% in 2018. The overall scale of non-attendance is probably due to the fact that most aspects of the festival are free of charge, meaning that pre-registration is a risk-free venture. Although no-shows were on a larger scale in 2018 (possibly due to exceptionally hot weather causing people to change their plans), the demographic patterns of those who chose to attend having registered was reasonably steady across both years.

By far the strongest predictor of attendance was having visited the festival in previous years. In 2017, $62 \%$ of registrants who had been before attended on the day, compared to $52 \%$ of registrants who had not previously attended. The comparable figures for 2018 were $57 \%$ and $38 \%$. Both of these disparities were statistically significant at $\mathrm{p}<0.001$.

Another effective predictor of whether registrants ended up attending was whether or not the person doing the booking had a degree or equivalent qualification. In $201752 \%$ of registrants who did not have a degree came on the day, while 59\% of those with a degree attended. The comparable figures for 2018 were $40 \%$ and $48 \%$. These results were statistically significant at $\mathrm{p}<0.001$.

Confidence in science was another factor. We asked registrants: "How well informed do you feel about science?" Among those who answered "Very well informed" or "Fairly well informed", propensity to attend the festival was higher than amongst those who gave other answers. In 2017, 58\% of registrants expressing a level of scientific literacy attended the festival, compared to $52 \%$ of others. The comparable 
figures for 2018 were $47 \%$ and $42 \%$. These results were statistically significant at $\mathrm{p}<0.01$.

A less reliable indicator proved to be levels of deprivation. Using IMD data, we split the registrants into two groups - IMD deciles 1-5 (more deprived) and d6-10 (less deprived). In both years, the IMD d1-5 group were less likely to attend, by $54 \%$ to $58 \%$ in 2017 and $43 \%$ to $48 \%$ in 2018 . Although both results are weakly significant at the $\mathrm{p}<0.05$ level, further analysis reveals some inconsistencies in the data - in 2018 the effect was more marked when we compared d1-3 with d4-10, where as in 2017 the effect was weaker, indicating a lack of expected linearity. We suggest, therefore, that this aspect be treated with some caution.

It is important to note that these different indicators are not independent. For example, we would expect that individuals who have previously attended the science festival would report higher levels of information about science than those who had not, and when we tested this using our 2018 data this proved to be strongly the case $(\mathrm{p}<0.001)$. An association is also seen between having a degree and feeling wellinformed about science $(\mathrm{p}<0.001)$. Because a high proportion of attendees have a degree, we might expect those who have attended before to be more likely to have a degree, and again this is the case, an effect which, while weaker than the previous two dependencies, is still significant at $p<0.001$. However we can still use these 'risk factors' for non-attendance to cumulatively narrow down groups of registrants to target, and we can see that likelihood of attending having registered falls as the cumulative numbers of these risk factors increases (Table 1): 


\begin{tabular}{|l|l|l|}
\hline Number of 'risk factors' & \% of registrants who attended & Number attending \\
\hline $\mathbf{3}$ & 41 & 281 \\
\hline $\mathbf{2}$ & 44 & 642 \\
\hline $\mathbf{1}$ & 51 & 1060 \\
\hline $\mathbf{0}$ & 63 & 715 \\
\hline
\end{tabular}

Table 1: Relationship between number of risk factors and likelihood of attending in 2018

Using this information, in 2019 the festival organisers decided to target certain groups with extra marketing information. At a date 16 days before the festival, registrants who had not attended the festival before and did not have a degree were identified. Those who lived in areas with IMD d1-5 were then sent an extra targeted email thanking them for registering and giving them some 'top tips' on attending the festival for the first time, in an attempt to encourage them to convert their registration to attendance. A total of 128 families received this email; confidence in science was not used as a determinant for receiving the extra communication as it would have reduced numbers in the target group too much.

In order to investigate the success of this tactic we looked at how the proportion of targeted families attending compared with the overall proportion of registrants who attended. We looked at this data for three years, with the intervention taking place in 2019 only. Analysing these results was complicated by the fact that, although overall numbers attending the festival were reasonably stable over the three years, the patterns 
of attendance - for example the size of groups that families registered in, and the proportion of attendees that did not pre-register - fluctuated wildly.

The results were as follows:

\begin{tabular}{|l|l|l|}
\hline Year & \% of all registrants* who attended & \% of target group* who attended \\
\hline 2017 & 51 & 39 \\
\hline 2018 & 42 & 30 \\
\hline 2019 & 30 & 20 \\
\hline * who had registered at least 16 days before the event
\end{tabular}

Table 2: Proportion of target group who attended LSF across a three-year period

Because the overall proportion of registrants attending fell over the three years, for reasons possibly connected to the weather and/or a growing propensity to register in larger groups, it is hard to compare the results year on year. This data therefore provides no evidence that the extra communication intervention was effective in encouraging members of our target group to attend.

\section{Community Pass 2018}

Distributing passes via schools proved to be less effective than the organisers had hoped; of 993 passes given out in this manner, only 16 were used, a response rate of under $2 \%$. This is not an unusual response rate for an unsolicited mailout; direct marketing company McCarthy and King state that "In trying to project response rates for a business plan, $2 \%$ could be considered an average response rate (although $1 \%$ is safer and more realistic)," (McCarthy \& King Marketing, 2019). However the response 
rate means that this method of distribution may be more suitable for very high volumes of material. Understandably, given that each Community Pass had a face value of $£ 10$, organisers were unwilling to distribute them in very large numbers.

In addition to the above, it is possible that there was some confusion between standard advertising material and the Community Pass in the minds of recipients. These factors combined led the organisers to conclude that using book bags was not an effective method of distributing passes in the future.

Overall, distributing the passes via community groups and events was more effective, with a response rate of $11 \%(41 / 375)$, meaning that $65 \%$ of pass holders came via this method. At a granular level, however, results were decidedly mixed. In situations where the organiser of the group or event had taken a personal interest in the project and had targeted appropriate families to receive passes, response rates peaked at $60 \%$. In other groups there were zero attendees, raising questions as to whether the organisers distributed the passes at all.

The importance of a personal interaction when the pass was distributed was illustrated by responses to the 2018 post-event survey, 13/23 of which answered yes to the question: "Did the person who gave you the pass personally explain to you what it was?" Responses included:

"She explained to me that the new scheme is encouraging people who lives in nearby community to attend the science festival."

"Really encouraged me to go and explained how it would be fun learning for my 3 year old."

The 132 remaining passes were distributed via a letterbox drop and attracted six visitors, an encouraging response rate of just under $5 \%$. Small numbers made this result 
unreliable and the organisers decided to repeat this method the following year in larger volume.

Out of 1,500 Community Passes distributed in 2018, only 63 were used, a rate of 4\%. Despite this disappointingly low level of response, one positive is that targeting to more deprived groups was effective, with $76 \%$ of pass holders whose postcodes could be analysed coming from IMD d1-3. In addition, 16/23 (70\%) of pass holders who completed a post-event survey said that they had not visited the festival before.

The organisers decided not to ask all pass holders about their educational background and attitudes to science on the day of the festival, partly in order not to interrupt their day too much and partly because in the past, respondents have given more positive answers to questions about science confidence when asked face-to-face rather than in an online survey (Canovan, 2019). However in some cases, this information could be gleaned from pre-registration forms completed by Community Pass holders. Of 30 individuals for whom this information was available, 10 (33\%) reported that they had a university degree or equivalent, as opposed to $1229 / 1898(65 \%)$ of other attendees, a result that, although small numbers are involved, is statistically significant at $\mathrm{p}<0.001$. However reported science confidence was broadly similar to the general population of LSF attendees, with 18/30 (60\%) of CP holders reporting that they were well informed about science compared to $1341 / 1886(71 \%)$ of others.

Given the discussion of fragile intentions to attend in the previous section, it is interesting that of the 23 respondents who completed our post-event survey, five who had not previously attended stated that the main attraction of the Community Pass was that "I was planning to attend anyway". It is possible that the pass may have provided an extra impetus to convert those intentions into action. 


\section{Community Pass 2019}

Of the 1,000 passes distributed by the local charity, 121 were redeemed by 110 individual family groups (some had received more than one pass). This response rate was similar to the $11 \%$ response rate via community groups in the previous year, but the charity's reach to such groups was much greater than that of event organisers, meaning that overall numbers were up. This method accords with those that museum administrators cited in their interviews with Feinstein and Meshoulam; the authors found that

\footnotetext{
"In many cases, the task of disseminating free passes and free or reduced-price memberships was delegated to collaborating social service organizations. An administrator in the Northeast justified this arrangement by observing that "we do not have the expertise or the resources or the staff hours to try to figure out who are the audiences that we should be targeting or that need that kind of help."
}

By contrast, of the 1,500 passes distributed by mail to households in target areas, 16 were redeemed by 15 households, a response rate of around $1 \%$. This method was chosen as a response to a small but promising letterbox drop response from the previous year; however the poor response to the larger targeted mailshot suggests that this method of distribution is ineffective.

The 2019 iteration of the pass was broadly effective in reaching the target audience. $69 \%$ of families gave postcodes in IMD d1-3, rising to $81 \%$ for $\mathrm{d} 1-5$, and $61 \%$ reported not having attended before. Of those for whom organisers held data via registration, 34/60 (57\%) did not have a degree or equivalent, compared to 406/1145 $(35 \%)$ of other attendees, again a result significant at $\mathrm{p}<0.001$. Reach to families with lower science confidence improved somewhat in 2019, with 32/58 (55\%) reporting feeling well informed about science compared to 785/1143 (69\%) of general attendees, an effect which was weakly significant at $\mathrm{p}<0.05$. 
Response to a request to complete a post-event survey was lower than in 2018 , but among those who did so $14 / 20$ said that they had been planning to attend anyway, with respondents stating that the pass had made this easier for them:

"I was planning to attend funds allowing, this took the strain off budgeting for a day out."

"It made affording to attend easier as I'm on disability benefits."

This finding provides some support for the idea that the pass helps to convert potential visitors into actual visits. Additionally, 16/20 stated that they would attend in the future.

The characteristics of Community Pass holders vis-à-vis the total festival attendance is shown in Figure 4:

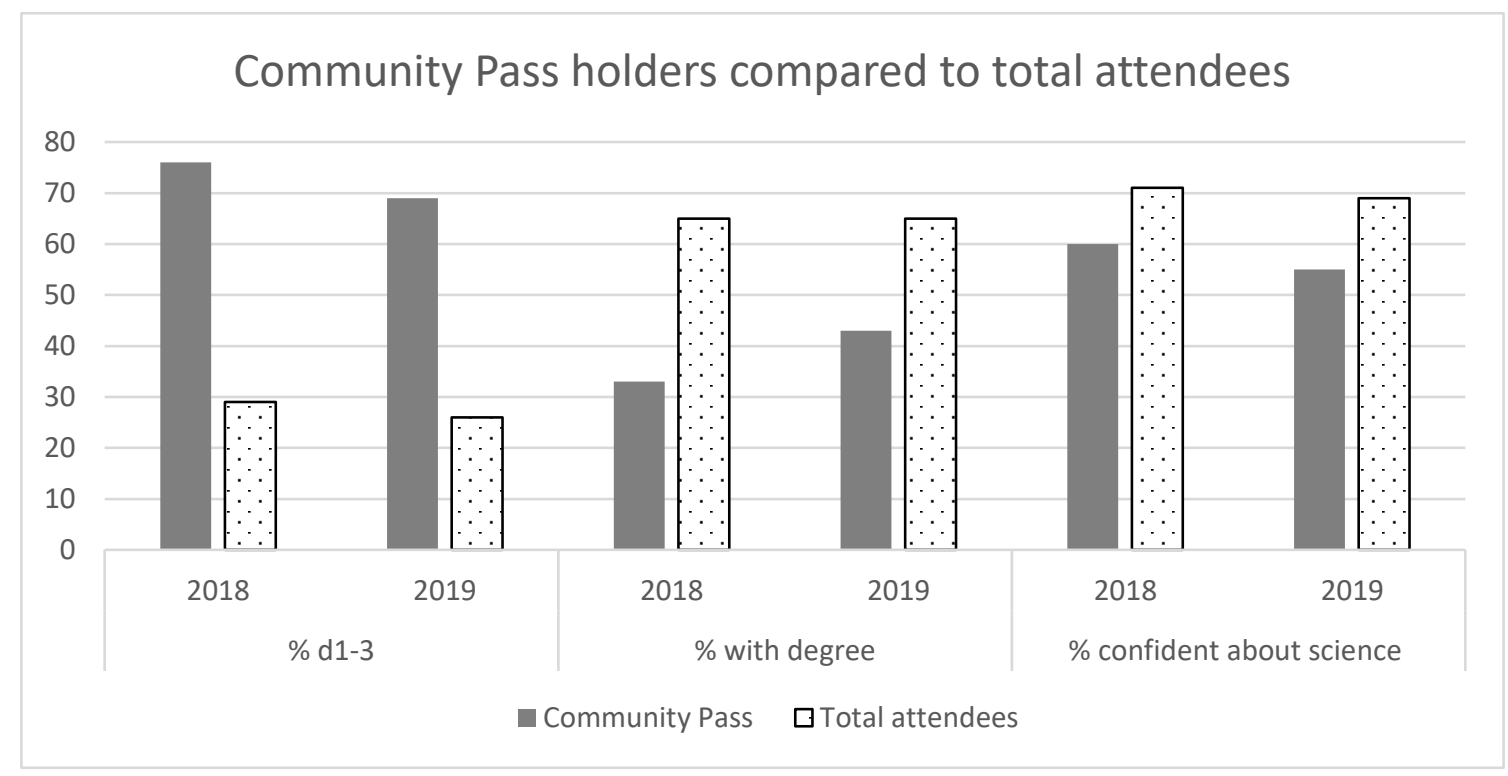

Figure 4: Demographic characteristics of Community Pass holders as compared to the whole attendee cohort. As can be seen, Community Pass holders are much more likely to come from areas of high deprivation (\% IMD d1-3), and are much less likely to have a degree. They are also a little less confident about science than other attendees. 


\section{Discussion and conclusions}

\section{Targeting underrepresented groups}

The experience of the LSF's Community Pass over the period 2018-19 illustrates the difficulty inherent in attracting underrepresented groups to a science festival. Despite making a no-strings offer of $£ 10$ per family in meal vouchers to attend, organisers struggled to attract large numbers of attendees through the scheme. However it should be noted that, given the financial implications for the festival - already a free event - it is understandable that the desire to reach more families with the Community Pass is in tension with the need to manage budgets, so the total of 125 families reached during the second year of the project was felt to be a reasonable outcome, with 200 the maximum that could have been accommodated in terms of cost.

It became apparent over the two years of the scheme that 'brute force' bulk methods of issuing the passes, such as indiscriminate distribution through book bags or area-wide mailshots, were ineffective for this type of scheme, with low response rates. Because each pass has a face value of $£ 10$, organisers were unwilling to distribute tens of thousands, due to the risk of misuse and the unpredictability of attendance levels.

The solution, however, seems to lie in tapping into established community networks. A response rate of more than $10 \%$ was achieved in both 2018 , when organisers worked to contact community groups, and in 2019 , when a local charity was used as an intermediary. Organisers preferred the latter approach, as in 2018 a lot of effort was expended in finding and contacting such local groups and getting the passes to them, with a small reach ultimately achieved. By contrast, the charity's existing networks allowed them to distribute the pass with greater ease, meaning that more families benefited in absolute terms. 
Families were targeted to receive the pass on the basis of SES only, with those who were resident in areas of greater deprivation or whose children attracted the Pupil Premium being the focus. This approach directly addresses only one problem - that of families of lower-SES being excluded from the standard festival audience. However, because both lack of university education and low science capital are associated with low-SES, we found that this approach also attracted families falling into these target categories. Attendees who came via the Community Pass scheme had a significantly different educational and SES profile than the bulk of attendees, and were somewhat less scientifically confident.

It should be noted that although the pass on the whole reached the target group, so that the population of Community Pass holders was very different from that of the LSF more widely, the numbers were not large enough to shift the overall balance of the festival audience. We find, therefore, that although such measures are useful to attract more members of low-participation groups to attend a science festival, they are unlikely to be effective in producing a more diverse population when looked at en masse. To achieve such a shift would be likely to require a much larger dispersal of funds, at which point it may be that the employment of a community liaison officer or similar might be a more effective method; more research is needed on this point.

\section{Bolstering fragile intentions to attend}

The fact that our target groups were not only less likely to attend science festivals overall, but were also less likely to attend having made a tentative commitment to do so in the form of a free pre-registration, is an interesting finding of this piece of research. Organisers and researchers made an initial attempt in 2019 to counter this tendency by providing higher levels of information to registrants in target groups; however due to strongly fluctuating attendance patterns between festivals, whether or not this had any 
effect cannot be said.

Interestingly, some Community Pass holders stated in the post-event surveys that they had been planning to attend anyway but that the pass had made this easier. Given our findings about fragility of intention to attend, it is possible that the pass was the deciding factor which tipped these families over into attending; however this is not a proposition that it would be easy to test.

The fact that post-event survey respondents stated that they would attend the festival in the future is an encouraging sign, given that we know that those who have attended before are more likely to attend again. It is possible, therefore, that the Community Pass scheme may have a 'trickle-down' effect in subsequent years.

This exercise has provided a valuable insight into the complexity of the challenge faced by festivals wishing to encourage underrepresented groups to attend; a multi-stage process is needed to first inspire a potentially fragile intention to attend, and then to support that intention to fruition, ending with a successful experience on the day.

\section{Conclusions and next steps}

This study shows that incentivising target groups to attend a science festival can be reasonably effective, albeit on a small scale. The most effective way of issuing such an incentive was found to be via local-level groups with good contacts in target communities; making personal contact with the recipient via community organisers was instrumental in encouraging families to use their pass and attend.

It is interesting to look at these findings in the light of the literature which suggested that the major barrier to museum attendance - and, by extension, attendance at other cultural events such as science festivals - was a lack of interest or time rather than financial considerations. Our 'fragile intentions' group had displayed an interest and indicated that they had time to attend by registering for the festival; the fact that 
many Community Pass holders said that receiving the help had made it easier to fulfil an already-held intention to attend may therefore be critical in encouraging this group. Lancashire Science Festival organisers are committed to continuing the scheme, refining the offer through each iteration in order to be as effective as possible. However a wider investigation into the effectiveness of financial incentives in affecting the overall balance of festival attendance, and the relative efficacy of other measures such as community interventions, will only be possible if a significantly greater financial investment is made. 


\section{Bibliography}

Archer, L., Dawson, E., DeWitt, J., Seakins, A., \& Wong, B. (2015). “Science capital”: A conceptual, methodological, and empirical argument for extending bourdieusian notions of capital beyond the arts. Journal of Research in Science Teaching, 52(7), 922-948.

Archer, L., DeWitt, J., Osborne, J., Dillon, J., Willis, B., \& Wong, B. (2012). Science Aspirations, Capital, and Family Habitus: How Families Shape Children's Engagement and Identification With Science. American Educational Research Journal, 49(5), 881-908.

Association of Independent Museums. (2016). Taking Charge - Evaluating the Evidence: The Impact of Charging or Not for Admissions on Museums. Retrieved from https://www.aim-museums.co.uk/wp-content/uploads/2017/04/ExecutiveSummary-Taking-Charge-\%E2\%80\%93-Evaluating-the-Evidence-The-Impact-ofCharging-or-Not-for-Admissions-on-Museums.pdf

Bultitude, K. (2014). Science festivals: Do they succeed in reaching beyond the “already engaged"? Journal of Science Communication, 13(4), 1-3.

Canovan, C. (2019). "Going to these events truly opens your eyes". Perceptions of science and science careers following a family visit to a science festival. Journal of Science Communication, 18(2), 1-18.

DeWitt, J., Archer, L., \& Mau, A. (2016). Dimensions of science capital: exploring its potential for understanding students' science participation. International Journal of Science Education, 38(16), 2431-2449.

Dilenschneider, C. (2015). How Free Admission Really Affects Museum Attendance. Retrieved from https://www.colleendilen.com/2015/08/12/how-free-admissionreally-affects-museum-attendance-data/

Feinstein, N. W., \& Meshoulam, D. (2014). Science for what public? Addressing equity in American science museums and science centers. Journal of Research in Science Teaching, 51(3), 368-394.

Kennedy, E. B., Jensen, E. A., \& Verbeke, M. (2017). Preaching to the scientifically converted: evaluating inclusivity in science festival audiences. International Journal of Science Education, Part B, 8(1), 14-21. 
Kirchberg, V. (1998). Entrance fees as a subjective barrier to visiting museums. Journal of Cultural Economics, 22(1), 1-13.

Martin, A. (2002). The impact of free entry to museums. Cultural Trends, 12(47), 1-12.

Nielsen, K., Gathings, M. J., \& Peterman, K. (2019). New, Not Different: Data-Driven Perspectives on Science Festival Audiences. Science Communication, 41(2), 254264.

Rose, K. M., Korzekwa, K., Brossard, D., Scheufele, D. A., \& Heisler, L. (2017). Engaging the Public at a Science Festival. Science Communication, 39(2), 250277.

Science Festival Alliance. (2017). 2017 Annual Report. Retrived from https://sciencefestivals.org/resource/2017-annual-report/

UK Science Festivals Network. (2018). UKSFN 2018 infographic. Retrieved from http://sciencefestivals.uk/wp-content/uploads/2019/02/UKSFN-2018infographic.pdf 